\title{
Sciences Teacher Education Curriculum Re-alignment: Science Education Lecturers' Perspectives of Knowledge Integration at South African Universities
}

\author{
Kwanele Booi ${ }^{1, *} \&$ Mamsie Ethel Khuzwayo ${ }^{1}$ \\ ${ }^{1}$ Faculty of Education, SP-FET Department, Cape Peninsula University of Technology, Mowbray, South Africa \\ *Correspondence: Faculty of Education, SP-FET Department, Cape Peninsula University of Technology, Mowbray, \\ South Africa. E-mail: booik@cput.ac.za
}

Received: November 13, 2017

Accepted: November 22, 2017 Online Published: February 7, 2018

doi:10.5430/jct.v7n1p52

URL: https://doi.org/10.5430/jct.v7n1p52

\begin{abstract}
A qualitative case study was conducted at six purposively sampled universities; out of a population of approximately 23 universities. This sampling strategy was based on selecting some universities that became Universities of Technology during the process of merging Higher Education Institutions (HEIs) while other universities kept their identity; currently being referred to as Traditional Universities. In-depth interviews and analysis of curriculum documents were used as sources of data acquisition to address the aim and questions explored by this study explored; necessitated by the need to implement Minimum Requirements for Teaching Education Qualification (MRTEQ) policy guidelines. The sampled universities' identities were concealed and pseudonyms were assigned to participants for ethical reasons. Qualitative methods were applied for data analysis. Findings revealed that for some institutions' integration of sub-disciples of science curriculum led to contestations and debates resulting from different philosophical perceptions held by subject specialists in the curriculum design process. Knowledge integration continues to be a contested field in universities that typifies resistance to change. Some participants demonstrated a positive disposition towards knowledge integration models which they used in curriculum development. This study concludes that a collaborative and collegial deliberation among science education lecturers and experts in various knowledge domains could be a way to find common ground on issues highlighted in this study. Re-thinking and re-conceptualising knowledge organisation for science academic knowledge are appropriate to the needs of school curriculum and benefit science teachers with knowledge and competences for knowledge impartation, skills and values in the subject.
\end{abstract}

Keywords: knowledge integration, curriculum development, multi-disciplinary model, science teacher education

\section{Introduction}

The principle of integration in curriculum research in teacher education and training was introduced as an integral component of outcomes based education. Introduction of integration had implications for organisation and structuring of subject content knowledge; from homogenous to multidisciplinary knowledge design (Gravette and Geyser, 2004; Jansen and Christie, 1999). The Norms and Standards Curriculum policy ushered in a new paradigm for teacher educators which Jansen and Christie (1999) considered to be a radical change; resulting in various misconceptions. Fullan (1995 and 2006) concludes that change is a process which is overloaded with new concepts, beliefs, attitudes, interpretations and misconceptions for those who are engaged in it. Literature highlights that there are protagonists for, and antagonists to, change. Resistance to change is viewed by researchers in the social sciences as a phenomenon that imposes challenges upon new innovations and reforms in education (Goodson, 1994; Fullan, 2006 and Apple, 2004). This study considers the beliefs, attitudes, interpretations and conceptions of science teacher educators to be critical in curriculum innovations in the Higher Education Institutions (HEIs). The principle of integrated knowledge and integrated learning underpins the curriculum policy for teacher education and training as stated in the Minimum Requirements for Teacher Qualification (MRTEQ), (DHET, 2015). Integrated knowledge and learning have implications for teacher educators in the field of sciences at universities. The theory that informs this principle declares that there should be a shift in the conceptualisation of knowledge from homogenous disciplinary to multi-disciplinary knowledge structure. MRTEQ's principle of integration in curriculum research in teacher education and training was introduced as an integral component of Outcomes Based Education and bore certain 
implications for the organization and the structuring of subject content knowledge from heterogeneous or multi-disciplinary knowledge design to integrated knowledge design (Gravette and Geyser, 2004 and Jansen and Christie, 1999).

According to Bernstein's theory of Codes and Modalities, the process of knowledge production is guided by principles; so changing from heterogeneous subject content knowledge to homogenous (integrated) subject content knowledge is perceived in this study to be an issue of main concern. Fullan (2006) concludes that curriculum change introduces new concepts, values, attitudes and interpretations which this study regards as an integral part of the process of curriculum development for teacher education qualifications at universities. Compounded with these critical issues is the notion of compliance with the espoused curriculum policy which could be viewed as a threat to some academic privileges such as the sort of institutional autonomy which universities have traditionally enjoyed. Contestations and debates were seen in this study as inevitable in matters concerning decision-making or philosophical and theoretical attributes in the process of curriculum development (Carl, 2012). These topics provided a background to the problem under investigation in this study which has been stated as follows: how science teacher educators conceptualized the knowledge integration principle as specified in the espoused curriculum as part of their practice and the approaches they thought were suitable for implementing the principle of integrated knowledge into the sciences education curriculum learning (pedagogy).

\section{Research Aim}

This study considers the beliefs, attitudes, interpretations and conceptions of Sciences Teacher Educators to be critical in curriculum innovations in Higher Education Institutions (HEIs).

\section{Research Questions}

- How did Sciences teacher educators conceive of the principle of knowledge integration in the espoused curriculum?

- What were the implications held by such conceptions and perspectives of knowledge integration portrayed by Sciences Education Lecturers in HEIs in South Africa?

\section{Literature Review}

\subsection{Contesting Approaches to Curriculum Programming}

Literature reveals that curriculum research in the $21^{\text {st }}$ century explores paradigms suitable for re-conceptualisation of curriculum design and development. Researchers such as Spady (1994) and Killen (2015) influenced curriculum research in their advocacy of Outcomes Based Education. This is considered by Spady (1994) and Sato (2003) to be part of meliorism in curriculum research. Outcomes based education, according to Carl (2015), is classified into three categories: transmission, transactional and transformational outcomes based education. Killen (2015) avers that the model of Outcomes based education adopted to introduce curriculum changes is chiefly transformational. Institutions of higher learning were to introduce outcomes driven curricula for their qualification programmes (Gravette and Geyser, 2004). Nkomo (1997) points out that institutions of higher learning need to shift from narrow conceptualisations of knowledge into broader fields of study in order to align their epistemological research with integrated knowledge and learning. Outcomes-based curriculum programming in South Africa encapsulated a new paradigm for knowledge organisation and integrated learning.

\subsection{Critical Analysis of Outcomes Based Curriculum and its Philosophical Foundations}

Researchers into Outcome Based Education (Spady, 1994; and Spady and Marshall, 1991) posit that a philosophy of OBE refers to an embodied and expressed set of beliefs and assumptions about learning, teaching and the systemic structures within which these activities take place. These researchers explain that early Greek philosophers (the Peripatetic scholars) regarded themselves as itinerant teachers whose basic concern was the love of wisdom; a praxis of which gave rise to the philosophical lexicon cherished today in philosophical discourse. Copleston (2003:287) posits the argument about the philosophical foundation of OBE around Aristotle's view concerning knowledge and man which emphasises that it is the nature of man to desire knowledge. Aristotle places the man who seeks knowledge for its own sake above him who seeks for knowledge of some particular kind with a view to the attainment of some practical effect (op.cit, 287).

According to Coplestone, (ibid.) the philosophy of Outcomes Based Education revolves around the concept of 
knowledge. This argument explicates philosophical foundations of Outcomes-Based Education through a careful revisiting of philosophical concepts associated with knowledge: as reality (ontology), its theory (epistemology), its dissemination (pedagogy) and its context (consciousness) which, when taken together, provide the basic principles for practical application. Coplestone (2003: 287) concludes that such principles can provide coherence to a wide array of outcomes-based education models and practices and lay a foundation for their successful implementation. Sampa (2014) challenges the assertion that OBE has no philosophical and theoretical foundations. The argument advocated by the findings of this research is that the term philosophy is used inappropriately by those researchers who associate it with dogmatic expressions: whereas philosophy means that man can think and reason in pursuit of wisdom.

Literature reveals that researchers into OBE and its curriculum design and development such as Spady and Marshall (1991), Spady (1994) and Killen (2015) highlight that conceptualisation of curriculum is informed by ideas of Constructivist theorists. The curriculum in this approach proposes that learners invent their own ideas through interaction with others and the environment. The learner selects and transforms information, constructs hypotheses, and makes decisions; its focus is on knowledge construction. Knowledge is constructed through personal experience, previous knowledge and beliefs. Learners have to be encouraged to discover principles by themselves; through varied opportunities for dialogue among their peers and with teachers. Teachers need to present information to be learned that matches or closely matches a student's current level of learning. The curriculum is to be organized in a spiral manner so that students continually build upon what they have already learned. The teaching strategies have to be diversified to suit student responses and encourage them to analyse, interpret and predict information in the course of their learning.

A similar sentiment was expressed in Semester (2007), Kemerling (2011) and Sampa (2014) when re-iterating that Outcomes based curriculum provides a dynamic approach to understanding learning outcomes; to include both emergent outcomes and unintended outcomes that are equally beneficial for the purpose of social enlightenment and transformation. In light of the constructivist knowledge paradigm, Spady (1994) (cited in Tavner, 2005:257), makes good sense in his conceptualisation of OBE as follows: the basic tenets of OBE are shifting the focus of educational activity from teaching to learning; skills to thinking; content to process; and teacher instruction to student demonstration.

Research into Outcomes-based curriculum highlights various perspectives; indicating beliefs and assumptions of researchers concerning the epistemological, ontological and axiological principles which underlie a curriculum (Sampa, 2014 and Dancy, 1991,). These researchers conclude that there are traces of relativism in the manner in which knowledge, reality, experiences and thoughts are explicated in the OBE curriculum. In relativist terms, all experience, thought or reality are relative to something else. This implies that all understanding is a form of interpretation using a lens of choice of some kind; such as culture, prior experience, status, gender and the like. Sampa (2014) affirms that relativistic ontology implies an existence of multiple realities, multiple answers, and multiple perspectives. OBE is defined as a process that focuses upon what is to be learned: outcomes are arguably an implication of the relativistic ontology (Kudlas, 1994). Spady (1994) claims that in Outcomes Based Education and its curriculum, it is more appropriate to speak of convergence or hybridization of knowledge than homogeneity or purity of reality: so that all knowledge provides only a limited aspect of reality or a version of it. In the context of Outcomes-based curriculum, all experience is mediated by experience.

Literature shows that Outcomes Based Education and its curriculum advocate an alternative perspective or approach to epistemology. Dancy (1991: 141) claims that OBE embraces a subjective epistemology; something which concerns itself with the creation and dissemination of knowledge. In a narrower way, epistemology deals with the study of knowledge and justified beliefs. Epistemology is conceived as a project of determining necessary and sufficient conditions for justifying knowledge claims and refuting scepticism. Subjective epistemology implies that the teacher and the student co-create understanding. It is not a unilateral process of transfer. If the call to learner-centred approaches to teaching and learning are invoked, this basic principle of OBE is implied. The teacher has something to offer; yet knowledge in this philosophical mode is a product of encounter between teacher and students. Convergence of thoughts and experiences justifies knowledge creation and refutation of scepticism.

In supporting the view of subjective epistemology, Spady (1994) claims that an outcome is a culminating demonstration of learning: a demonstration of learning that occurs at the end of a learning experience. It is the result of learning which is a visible and observable demonstration of three things: knowledge, combined with competence, combined with orientations (Killen, 2003: 23). This epistemic foundation for knowing things is seen as essentially propositional knowledge which can be more or less complete, justified inferentially and, on the basis of experience, 
can be communicated (Dancy and Sosa, 1993:240).

\section{Theoretical Framework}

Theoretical framework underpinning this empirical study was based on Bernstein theory of knowledge production (Bernstein, 2000) and Maton's Legitimation Codes Theory (Maton, 2014). Morais and Neves (2001) underline Bernstein's theory which emphasises the unique nature of knowledge as defined by its subjective formation in the mind of the knower. Knowledge production models provided by Bernstein's theory in Davis (2001) explain that modalities in subject knowledge production generate a unique syntax and semantics. Bernstein (2000) emphasises the distinctive features of each subject: each subject has its code modalities and those are the determinants or principles regulating knowledge production. Similarly, Maton (2014) in agreeing with Bernstein, argues that the Legitimation Codes theory confirms that knowledge is classified according to specific codes which provide recognition rules.

Moore and Young (2010) challenge the schools of thought that promote the view of subject knowledge as distinct realities. These researchers point out that certain models of curriculum design and development [those dominated by a set of assumptions about knowledge production as neo-conservative traditionalism and technical-instrumentalism] serve the cognitive and technical agenda. Students or teachers 'produced' by such curricula are seldom competent, creative and critical thinkers: key abilities required in the 21 st century. In endorsing knowledge integration from Mode 1 [which is a heterogeneous discipline or taxonomy of discipline] to mode 2, the shift to the amalgamation of disciplines is made plain. In respect of Sciences teaching (Gibbons et al, 1994) and Fullan (2006) assert that teachers should be grounded in a plethora of themes: Biological sciences (animal and plant anatomy and human physiology) Paleontological studies and biomedical studies, Ecology and Biochemistry, chemistry, Physics, and Geography. Conceptualisation of sciences in the school curriculum indicates that knowledge of science entails a broad field of knowledge: the animal kingdom, chemistry, biochemistry, microbiology and human physiology, physics, geology and geography.

The neglect of knowledge integration in the university curriculum deprives teachers of Sciences of an opportunity to learn about the inter-relatedness and inter-connections between the subject content areas in Sciences. Killen (2015:91) points out that "school learners cannot be expected to integrate knowledge within and across the subject boundaries without considerable guidance of the teacher who is competently trained". Jansen and Christie (1999) note that hybridisation of knowledge in teacher education introduced a paradigm for teaching and learning in universities which is a way of aligning teacher training with transformation in the school curriculum. The argument stresses that hybridisation of knowledge requires competences and expertise of teaching across traditionally heterogeneous subject content.

\section{Methodology}

The case study research design was used for collecting data through in-depth interviews and curriculum design and development document analysis (Babbie and Mouton, 2007). The purpose of the choice of this methodology was to gain insight into how teacher educators in sampled institutions navigated the progress of designing and developing sciences curriculum as mandated by MRTEQ policy. Two to three Sciences educators who were involved in the process of re-curriculation of sciences education curricula were purposively selected from six institutions that were used as a sample of the study based on the following attributes: 1. Three universities were formed as a result of merging Higher Education Institutions; 2. Three institutions kept their status as traditional universities.

Kumar, 2005 defines in-depth interviews as face-to-face engagement between the researcher and the participants directed at understanding informants' perspectives/perceptions on the experiences or situations and expressed in their own words. The questions asked during interviews were prepared or structured before the arrangement of the interviews. The participants were asked the same set of questions seeking data to answer the questions on their conceptions and perspectives of the knowledge integration in sciences disciplines that form sciences education as well as their views and perceptions on compartmentalising of different subjects that have been integrated to form a multidisciplinary subject which became natural sciences in school curriculum. Permission was sought from the universities' gate keepers and interviewees to collect data through in-depth interviews as well as documents that were used for recurriculation of Sciences teacher education. Permission to use an audio-recorder during the interviewing process was sought from all participants. The transcripts were then developed after the interviews for analysis purposes. The analysis of the following documents was carried out: (i) Templates outlining the proposed scope of content for Sciences education curriculum, (ii) proposed natural Science course outlines for all year levels 
in the Bachelor of Education qualification informed by MRTEQ policy were requested. Data collected by means of document analysis were used to triangulate information collected through in-depth interviews (Babbie and Mouton, 2007; Cohen, Morrison and Manion, 2012).

Ethical clearance to conduct the study was obtained from the university where the researcher is registered for the study. Written consent was sought from every participant in the study undertaken and in the consent form the purpose of the study was explained: the role played by each respondent was made clear. A copy of the consent form was made available to stakeholders involved in this particular study before interviews were conducted. In the consent form, the universities who participated in the research were given a written consent form to be signed by the heads of research of the institution, heads of department in the institutions where the study was conducted and to individual curriculum designers and developers of sciences education curriculum who participated in the study. Anonymity of the institutions and curriculum developers were taken into consideration and as such, code names for institutions and pseudonyms for individual curriculum designers and developers were used throughout the study.

\section{Results}

\subsection{Interviews}

Theme 1: Patterns of thought that are negative towards knowledge integration.

In the sample of thirteen $(\mathrm{n}=6)$ academics, $25 \%$ of volunteer participants were not in favour of knowledge integration. Data from this $25 \%$ group strongly suggested that integration of knowledge within distinct disciplines that form Sciences education as a multidisciplinary subject compromises depth of knowledge in various disciplines: such as Physics, Chemistry, Biology, Zoology.

One respondent, who typified this attitude towards integration of knowledge stated:

It is very difficult to construct a programme, so that at least there can be some kind of knowledge depth in each on these disciplines. And we still have that kind of challenge.

Another respondent stated:

With this concept of integration of knowledge coming to the fore when I am thinking environmental education but in Natural Sciences it is not catered for. I see myself going back to compartmentalisation. It is difficult to integrate different disciplines because in one course, Natural Sciences and Natural Sciences should this be repeated twice?, there are four different lecturers and the tendency is to look at your area of speciality.

These utterances are substantiated by Bernstein's theory of knowledge production which promotes the principle that disciplines or subjects are distinct on the basis of their unique syntax, codes and modalities. These key elements or criteria provide in-depth knowledge of a subject. The distinctive nature of subject-content knowledge was affirmed by a respondent who stated that:

This implies that knowledge will be diluted to accommodate disciplines that are clustered to form a multidisciplinary subject or a broad-field subject which has been formed through knowledge integration.

Finding: data highlighted that academics represented in this view in the sample were resisting the international trend in knowledge production which proposed a shift from heterogeneous subject content knowledge to hybridisation of knowledge from various related disciplines (Gibbons et al., 1994; Fogarty, 1991).

The implications: This pattern of thought that appeared to be negative towards adoption of such international trends in knowledge production was not held by the overwhelming majority of participants in the sample. In this study such a reactionary, retrogressive trend is concerning: all academics should provide sciences teacher trainees with knowledge that enables them to implement changes and meet the objectives of the espoused curriculum. Contestations about knowledge organisation and selection of subject content knowledge in the curriculum for Natural Science education and training are viewed in this study as detrimental to the production of competent Sciences teachers in South Africa.

Theme 2: Patterns of thought that indicated positive inclinations and dispositions towards knowledge integration.

Category A: Partnerships to ensure relevance of teachers' academic subject content to teach a Sciences curriculum in schools.

The first cluster of academics in this category raised issues of concern about reports which they received from stakeholders and their postgraduate students teaching Natural Sciences in schools. A typical volunteer participant's statement confirming such concerns claimed that: 
Schools are still teaching fragmented sciences at school despite the presence of CAPS. The lack of qualifications and expertise to teach school science is one of the problems that have been highlighted as a challenge in the Eastern Cape. Lack of content depth among teachers teaching integrated science subjects in grade 8 and 9 has been highlighted as a challenge hence a program Fundisa was introduced through a joint venture between the Eastern Cape government Department of Education and one of the universities in the Eastern Cape.

Such views sustained the rationale for maintaining heterogeneous disciplines in the curriculum for teacher education and training of Sciences. The main reason adduced for maintaining separate disciplines was students' inability in their first year at university to comprehend simple basic conceptual knowledge in disciplinary content-knowledge. This concern was raised by, for example, respondent $\mathrm{J}$ when stating:

To integrate things that cannot be integrated within the same discipline of natural sciences, I refer to it as forced integration. You cannot integrate everything; there are certain themes that cannot be integrated.

Data classified under this category indicates that academics who shared this pattern of thought understood the importance of aligning the curriculum for preparing Sciences teachers with the needs of students, the expectations of the work place and the national Sciences curriculum for schools called Curriculum Assessment Policy Statement (CAPS). The idea of partnership between universities and the Provincial Department of Education is viewed by this study to be a symbiotic collaboration to ensure that competent school Sciences teachers are academically and professionally equipped to implement curriculum changes into a Sciences school curriculum. Respondents regularly alluded to 'knowledge integration for teaching grade 8 and 9' which supports the usefulness of integrating all spheres of disciplinary knowledge to enable Natural Sciences in the senior phase school teachers to teach content more effectively.

Category B: Semester courses, modularisation and thematic approach

This category was identified from data and indicated a positive inclination towards knowledge integration which emphasised modularisation of themes across disciplines in the broad field of Natural Sciences: Geography, Physical Science, Chemistry and Life Sciences such as observed in the plant kingdom and animal kingdom. Participants who shared this view highlighted in their responses that themes should be organised on a semester basis to enable students to navigate through related themes from a subject's knowledge. Respondent X stated:

We use semester courses with all four sub-disciplines catered for. Currently we are using a thematic approach to ensure that related content offered caters four all discipline. Respondent $\mathrm{F}$ reiterated this view: integration deals with more advanced approaches of Natural Sciences teaching: e.g. food security. Integration is a sort of mind map which focuses on plant and animal production, plant genetics, pest control, bacteria, viruses and agriculture. Similarly, Respondent G added that: Modules are worked out per semester e.g. third year Biochemistry (photosynthesis and respiration).

Participants expanded on this notion of knowledge integration by providing a rationale for modularisation of disciplinary knowledge for Natural Sciences teaching into themes in the first and second year science education curriculum before they chose sub disciplines offered in third and fourth year curriculum which aims at giving them an opportunity of specialisation for FET school curriculum. This was what respondent H stated:

It is like for example learners find it quite difficult to understand inertia, they say ok, what is inertia? And I say you sitting there can you be there forever according to physics? And how can I make you stand up, they say I have got to apply force, then I say in their Natural you do not say apply a force, it is about me forcing you to leave that place. I said oh, why do you say force, then I say whenever we use force in everyday language, it is about resistance. You are asked to do something you don't like. And that resistance in this example is INERTIA. That can link on how we talk in everyday Natural and also the same concept includes what is in the school curriculum so that at least our teachers can cope with what is in the school curriculum at the moment.

This category embraced the thematic approach as a means of showing interconnection and interrelatedness in selection and organisation of academic content knowledge for Sciences teaching in schools. A thematic approach focuses on the vertical articulation of knowledge from basic, simple conceptual and theoretical knowledge to complex and advanced knowledge. Other respondents identified with this disposition:

Knowledge should be organised from cellular to systems level in Sciences which organises Sciences knowledge using taxonomy or nomenclature.

Finding: The concept of integration in this category emphasises organisation of Science education themes from related sub-disciplines in a vertical order; whereby simple and basic conceptual knowledge is presented during the 
first semester. The complex content from some sub-disciplines was set for second semester modules.

The Implication: Each discipline should be handled differently. A contrast was identified in other responses which indicated that four components, Geography, Physics, Chemistry and Life Sciences are to be treated as sub-disciplines taught in two semesters in each year. Similarly, these data revealed the significance of knowledge integration for solving Natural problems: respondent H stated:

For example issues of food security and production can be understood as part of knowledge integration at an advanced level.

The data associated with this pattern of thought points out challenges encountered by students teaching broad knowledge of Science at schools. Such challenges informed the design and development of the Sciences curriculum in the reviewed program. Consideration of the need for infusion of topics into the reviewed curriculum came into being because there were gaps in student knowledge. One lecturer indicated:

I need to infuse some Chemistry and some little Physics, [some little bit of this and little bit of that] so that when they leave here after the four years they would have Natural Sciences and at least they would have been exposed to the theoretical part or understanding for instance the periodic table, atomic theory, a bit of optics and a bit of that.

Another lecturer from the same institution stated that her practice is based upon alignment of the curriculum she teaches her students with the school curriculum:

Natural Sciences discipline is a basket science because we draw from different disciplines and sub disciplines. It is philosophy driven subject. Taking a bit from different disciplines make the subject unique and currently, social sciences play a pivotal role in science teaching (social sciences, social justice, language and philosophy) feeding in the teaching of science hoping to get credible, viable, product that will enrich somebody as well as me, as a teacher educator. Science is not factual and as such there are so many disciplines acknowledged in the sciences. Natural Science is not exactly like other sciences ... Social aspects are taken into consideration and acknowledging these aspects within the discipline adds value to the uniqueness in Natural Sciences. There is quite a lot that is feeding into Natural Sciences to make it an integrated discipline.

Findings: data presented under this category indicate that academics may differ in their thinking with regards to knowledge integration but work towards a common end, which is integration. Fogarty (1991) provides a wide range of approaches to knowledge integration: that it is concerned with inter-relatedness and inter-connections which could be exploited by the aligning of themes or linking up overlapping concepts. The idea of a modular approach was popular among academics and this finding pointed to the fact that this is the common practice among academics which could address the challenge for appropriate and competent academic knowledge required by teachers to teach Sciences across phases effectively.

Implications: The patterns of thought revealed by academics in the sample about integrated knowledge imply a shift away from conceiving knowledge in terms of heterogeneity and towards hybridization of knowledge. The implementation of this shift is viewed in this study as a positive signal towards producing internationally competitive Sciences teachers who will make teaching and learning of Sciences multidisciplinary knowledge more meaningful in schools. Exposition of academic content knowledge for integrated Sciences teaching could benefit teachers and learners in schools. For teachers, this could mean they demonstrate competence in playing their roles fully in terms of; phase specialisation, programme interpretation and programme planning as well as subject specialists. Learners of Natural Sciences in senior phase at schools could benefit from teachers who present Natural Sciences subject content knowledge in an inter-related manner. Learners can understand knowledge as an integrated system which requires transferability of conceptual knowledge as well as skills (Gibbons et al, 1994, Kutti, 2010 and National Qualification Framework, 1996).

\subsection{Analysis of data collected by means of documentation}

It was indicated above that the documentation that was developed during the process of curriculum review was to be analysed. The purpose of the analysis of documents was to find information related to the final decision on what should go into the blue print as an approved curriculum for educating and training Sciences teachers. From the findings of interviews, it was clear that academics in the same institution manifested diverse views of approaches and models to be adopted as confirmed by curriculum documents presented.

Data from documents showed that the curriculum blue print did not reflect clear and explicit learning outcomes, according to pioneers of OBE (Spady 1993; Killen, 2015and Biggs, 1994) comprising of a broad statement which encapsulates competence and abilities, the planned subject content which learners develop. Biggs (1994) proposed 
alignment of learning outcomes, content and assessment criteria in the Module or courses outline. The assessment criteria involve proof that the outcomes were attained.

Finding: Learning outcomes identified from the curriculum documents presented learning outcomes as assessment criteria: for example, 'after completion of this module, students will be able to' or 'describe the characteristics/discuss the structure and functions of'... etc.

Implication: The findings manifested that non-alignment of learning outcomes and content as well as assessment criteria could have negative implications for implementing the curriculum. The discrepancy noticed in other curriculum documents was the omission of the assessment criteria or the fact that only assessment methods were highlighted.

\section{Discussion}

Issues of deductive and inquiry learning point to the fact that academics contemplate any shift away from a content-driven paradigm to either competence or outcome driven paradigms for curriculum development and adaptation still remains an impediment to transform and align sciences teacher education curriculum. Interpretation of a deductive approach as conceived by the respondents in learning and knowledge generation entails logic and reasoning in the acquisition of disciplinary content knowledge and subject pedagogical content knowledge. In this view, a deductive approach could be suitable for enabling students to teach integrated Sciences disciplinary knowledge effectively in the classroom. The perception of the curriculum design and development held by academic proponents was that a deductive principle should underlie the selection and organisation of Sciences - disciplinary content knowledge as well as its subject pedagogical content knowledge. The inference of the Dialogical Argumentation Instructional Model (DAIM) attests that academics support vertical articulation of knowledge for skills and competences development rather than rote learning through content driven approaches (Ogunniyi, 1996; Ogunniyi and Hewson, 2008; Killen, 2015, and Morrow, 2007).

According to Zalaghi and Khazaei (2016), deductive principles in learning emphasise the identification of objectives which are based on definitions of assumptions. Deductive thinking was identified as an issue in analysis and interpretation of data because it provides a clue to what academics consider to be integration of subject content knowledge (SCK) and subject pedagogical content knowledge teaching of Sciences as a broad field of study or Learning Area (LA). Zalaghi and Khazaei (2016) explain that a deductive approach enables students to identify various components of the phenomena and their interrelations using logical reasoning. This argument indicates that students are able to draw their own conclusions through inquiry learning and experiential learning while they unpack definitions and assumptions presented by theorists in subject content knowledge. Zalaghi and Khazaei (2016) emphasizes that assumptions are generated through argumentation which begins with a theory and leads to new assumptions which are tested via comparison with observations, and finally accepted or rejected. This implies that Sciences students should be engaged in the argumentations so that they will generate their own assumptions based on theoretical knowledge. The other critical aspect in this discussion is the inductive approach which was highlighted during data analysis.

\subsection{Challenges Leading to Academics' not Complying with the Higher Education Qualification Framework Policy}

Findings from analysis of data highlight that, although curriculum blue prints were approved by the Higher Education Qualification Committee (HEQC) of the South African Qualification Authority (SAQA), implementation of such approved curricula remains a challenge. Another problem highlighted by the findings related to encapsulation of school needs in the selection of academic disciplinary content as well as pedagogical content knowledge. The issue of reviews of school curriculum affected teacher education and training. Debates and contestation regarding what should be part of curriculum design and development for Sciences curriculum delayed the process of curriculum review at some institutions. Alignment of teacher education and training with changes and continuities of school curricula was promulgated in the DHET (2011 and 2015). According to this alignment, curriculum for teacher education should be designed and developed in such a way that Natural Sciences teachers can teach across the two phases in different bands. This means that a Natural Sciences teacher should be able to teach subject content from senior phase (SP) grades (7, 8 and 9) in the General Education and Training Band (GET) and to further education and training phase (FET) grades (10,11 and 12). The implications for these changes in school curriculum obliged academics to think carefully about the model to be adopted in the organisation and selection of subject content to meet this critical need of schools as stakeholders. Selection and organisation of content knowledge required academics to ensure that teachers who taught in their institutions met conditions of employment. 
Contestations in curriculum design and development of the discipline by researchers such as Carl (2015), Schubert (1986), Null, (2011) and Kelly (2009) are informed by philosophical and theoretical paradigms. Academics adopt different philosophical foundations for a curriculum. According to Ornstein and Hunkins (2012), academics could propose the adoption of an essentialist philosophy to underpin the curriculum for the purpose of ensuring that a particular curriculum is relevant to the essential needs of a society and the expectations of all stakeholders. According to researchers such as Ornstein and Hunkins (ibid.), there are academics who strongly believe in the perennial philosophy: the interest of these academics in curriculum design and development is to pursue the view of knowledge as a product of absolute positivism. Pedagogical approaches linked to this philosophy promote acquisition of factual knowledge without questioning it. Schubert (1986), comments that a perennialist curriculum emphasises an analytic-empirical paradigm in knowledge production, teaching and learning.

Critics of the perennial philosophical foundation in curriculum design and development condemn it, however, for serving a technical interest which prepares teachers who will perform reproductive teaching (Grundy, 1994, Kelly, 2009 and Null, 2011). A technicist curriculum in teacher education and training is criticised by Ornstein and Hunkins (2012) for producing teachers who are transmitters of knowledge from sources to learners without any critical intervention or interpretation; as a result learners become passive recipients of what they are told is 'factual' knowledge.

The findings in this investigation indicate the prevalence of patterns of thought that are informed by perennial philosophy. During the process of data analysis, certain dispositions manifested an inclination in support of perennial philosophy and an analytic-empirical paradigm.

The conclusion from contestations and robust debates indicated that the curriculum that was approved by the DHET for these institutions could not be effectively implemented due to the fact that the implementers were not unanimous or in full support of the philosophical foundation underpinning the curriculum. It was concluded that the possibility existed that contestations on these critical issues could cause misunderstanding and obstruct effective implementation.

\section{Conclusions}

The difficulties highlighted by the findings in this study indicate that the chief problem lies not with the teachers but emanates from the curriculum on which science teachers are trained. Science teachers do not demonstrate applied and practical competences in areas of theoretical and practical knowledge because they have not mastered these skills in their basic education and training. The diverse interpretations of curriculum change postulated in the National Curriculum Policy for teacher education and training could pose a threat to the transformation of education in South Africa. If the curriculum for Science education teacher training fails to complement the changes and innovations introduced in the national school science curriculum, there is likely to be chaos. The subsequent result of this chaos could manifest in a high failure rate of students in the subject. The situation could be that of exchanges of view, where researchers at universities blame schools and provincial and national departments of education for failure to design an effective school curriculum. Schools and departments on the other hand blame universities for educating and training teachers who are not competent to teach school subject content knowledge. Science teachers are expected to teach Science and Technology in senior phase and Specialisation Sciences in Further Education and Training phase.

The importance of natural-long learning and openness to learning is crucial for Science academics; particularly those who are involved in teacher education. The paradigm of interpreting the unfolding realities in various spheres of world systems is cogent: economic, social, environmental and politics require re-thinking and re-conceptualised knowledge systems in the teaching and learning of Science. Knowledge Integration through hybridisation of related disciplines permeates research in South Africa and globally. Since its inception in 1997, the South African Qualification Authority (SAQA) and (NQF) has advocated educational and curriculum change. These bodies propound transformation in a democratic South Africa; embracing and pioneering integration of knowledge and learning. This liberal stance indicates that research and natural long learning should define transformation in all sectors and structures in educational institutions, universities and other institutions of tertiary education and training.

For the sake of pre-service Science teachers and the realisation of national educational goals, the science education specialist and teacher educator should find common ground for conceptualising the needs of Science teachers in a reviewed curriculum. Such common ground would overcome the issue of lack of uniformity in the education and training of competent science teachers for National Science school curriculum and its changes. Consensus on issues of philosophical beliefs and fundamental foundations for Science education curriculum would greatly benefit South 
African Science teachers of the $21^{\text {st }}$ century.

It is the nature of academe that allows contestations and robust debates and generations of theories in universities. Academics are known for intellectual engagement about issues related to the nature of things, structures and operations. But blatantly flouting conformity to curriculum policy is not helpful: some academics continue to claim that there was nothing wrong with the maintenance of heterogeneity in disciplines in Science Education. This stubborn, and often ignorant, perception of knowledge integration has detrimental effects for science teachers nationally and impedes learners' understanding that Science is about exploring new ways of thinking and testing structures in order to understand connections and relations. For example, contemporary issues raised in the United Nations Organisation's Millennium Development Goals (MDGs) and currently UNESCO's Sustainable Development Goals (SDGs), could focus integration of Science curricula: poverty and unemployment, environmental sustainability, child mortality, HIV/AIDS, malaria and other diseases. Deductive approaches to learning could enable students to navigate concepts within the disciplines including indigenous knowledge systems. Skills and competences acquired through engagement could enable science students in teacher education to produce knowledge verify new findings through testing or experimentation and explain them in an appropriate context.

Knowledge integration could be a paradigm shift for the development of science education curriculum for teacher education and training. Integration could as well be the principle underpinning implementation. The synthesis of the findings of the study highlighted issues that typify confusion and uncertainty regarding the interpretation of the DHET's (2011 and 2015) notion of integration and integrated learning of science education. The questions raised by the study are: How can academics and teacher educators hold diverse conceptions about the fundamental issues underpinning the curriculum and yet produce quality science teachers to implement the school curriculum? Are there possible ways in which academics from Science education departments can debate and engage with each other constructively to establish common ground on knowledge integration?

The study concludes that there are academics in Science Education departments who still adhere doggedly to traditional ways of teaching their own specialised disciplines. They are adamant that their practice is informed by renowned educational theories and philosophies. The findings of this study convincingly show that there is a worrying bifurcation in the interpretation of the notion of knowledge integration. The theoretical and practical implications of knowledge integration received diverse interpretations from academics in some Departments of Science Education which differed from those of formulators of the National Curriculum guidelines for MRTEQ.

The issue of non-conformity to the curriculum policy creates a grave division between teacher education and training and expectations encapsulating the needs of South African schools after 1994.Clustering subjects in the field of sciences in the school curriculum requires qualified teachers to teach across knowledge domains: for example in the Natural Sciences the teacher in senior phase (grade 7, 8 and 9) should have knowledge of Physics, Technology, Chemistry and Life Sciences. This implies that a Science teacher should be able to present conceptual and factual knowledge in an integrated format for senior phase learners to understand interconnections and interrelations between concepts; which could lead to learners being able to transfer knowledge and skills across knowledge domains and epistemologies. This integration could enable learners to acquire basic conceptual knowledge for Natural Sciences long learning through the transfer of knowledge and skills.

This study confirms the claim expressed in Fullan's theory of change that characterizes the fears and arguments of resistant implementers: change of curriculum introduces new beliefs, objectives and values which threaten the old guard. Adaptation of curriculum forces implementers to move out of their comfort zones and adjust to new thoughts, behaviour and actions. Fullan (2006) points out that resistance is inevitable during the implementation of curriculum changes and innovations.

This study advises that a collaborative and collegial deliberation among science teacher educators and experts in various knowledge domains could be a way to find common ground on issues highlighted in this study. Re-thinking and re-conceptualising knowledge organisation for science academic knowledge appropriate to the needs of the school could be of great value in equipping science teachers with knowledge and competences for effective teaching of knowledge, skills and values in the subject. Through research and conferences academics engage in scholarly networks to share and exchange ideas: so issues of integration in sciences instruction may be resolved by open debates and constructive networking. Institutions of higher education in many countries provide guidance for transforming education and producing teachers of high quality. The situation revealed by this study indicates that universities have not transformed their fundamental systems of thought: particularly with regards to teacher education and training. The findings indicated that the National School Curriculum and the National Curriculum Policy for teacher education point in the same direction yet, by contrast, academics in their Faculties of Education 
face in the opposite direction.

\section{References}

Babbie, E., \& Mouton, J. (2007). The practice of social research (7th Ed.). London: Oxford University Press.

Bernstein, B. (2000). Pedagogy, symbolic control and identity: Theory, research and critique (Revised edition). Oxford: Rowman \& Littlefield.

Biggs, J. (1994). Enhancing teaching through constructive alignment. Higher Education, 32(3), 347-364. https://doi.org/10.1007/BF00138871

Carl, A. E. (2015. Teacher empowerment through curriculum development. Theory into practice. ( $5^{\text {th }}$ edition.). Cape Town: Juta \& Company Ltd.

Cohen, L., Morrison, K., \& Manion, L. (2012). Research Methods in Education. New York: Routledge.

Copleston, F. (2003). A history of philosophy Vol. 1: Greece and Rome. London and New York: Continuum.

Council on Higher Education (CHE) (2010). Report of the task team on undergraduate curriculum structure. Pretoria: Government Printers.

Council for Higher Education. (2010). Annual report for Council for Higher Education: 2009/2010. Pretoria:

Dancy, J.J. (1991). Introduction to contemporary Epistemology. Massachusetts. USA. Blackwell publishers

Davies, B. (2001). Introduction. Towards a Sociology of pedagogy: The contribution of Basil Bernstein to research. New York. Peter Lang Press.

Department of Education, (2000). Norms and standards for educators. Pretoria: Department of Education.

Department of Education, (2006). The national policy framework for teacher education and development in South Africa. Pretoria: Government Printers.

Department of Higher Education and Training (2011a). Policy on the minimum requirements for teacher education qualifications. Pretoria: Government Printers.

Department of Higher Education and Training. (2011b). Integrated strategic planning framework for teacher education and development in South Africa: 2011-2025. Pretoria: Department of Higher Education and Training.

Department of Higher Education \& Training. (2015). Minimum Requirements for Teacher Education Qualification. Pretoria: Government Printers.

Du Toit, G. (2011). Conceptualising the re-design of curriculum for teacher education. Acta Academia (43), 107-131

Fogarty, R. (1991). The Mindful School: How to integrate the curricula. Palatine, IL. Skylight Publishing Inc.

Fullan, M. (2006). Change theory: a force for school improvement. Centre for strategic education seminar series. Paper no. 157, November 2006.

Gibbons, M., Limage, C., Nowotny, H., Schartzman, S., Scott, P., \& Trow, M. (1994). The new production of knowledge: The dynamics of science and research in contemporary societies. London: SAGE publications

Goodson, I.F. (1994). Studying curriculum. Buckingham: Open University Press.

Gravette, S., \& Geyser, H. (2004). Teaching and learning in higher education. Pretoria: Van Schaik.

Grundy, S. (1994). Curriculum: Product or Praxis. Philadelphia: The Falmer press.

Hoadley, U. (2010). Tribes and territory: contestation around curriculum in South Africa. In F.W. Pinar (Ed). Curriculum studies in South Africa: Intellectual histories \& present circumstances. New York. Palgrave MacMillan (pp. 125-176).

Jansen, J. D. (2002). The state of higher education in South Africa: from massification to mergers. Pretoria: Unisa.

Jansen, J. D., \& Christie, P. (1999). Changing Curriculum: Studies on Outcomes-based Education in South Africa. Juta: South Africa.

Killen, R. (2015). Teaching strategies for quality teaching and learning ( $2^{\text {nd }}$ Ed.). Van Schaik. South Africa.

Kudlas, J. M. (1994). Implications of OBE: What you should know about outcomes-based education. The Science Educator, 61(5), 32-35 
Kumar, R. (2005). Research methodology ( $2^{\text {nd }}$ ed.). London: Sage Publications.

Kutti, K. (2007). Design, Research, Disciplines and the new knowledge Production. International Association of Societies of Design Research: The Hong Kong Polytechnic University conference, 12-15 November, 2007.

Maton, K. (2014). Building powerful knowledge: the significance of semantic waves. In Rata, E., \& Barrett, B. (Eds.), The future of knowledge and the curriculum. London: Palgrave Macmillan.

Moore, R., \& Young, M. (2010). Reconceptualising Knowledge and the Curriculum in the Sociology of Education. In Maton, K., \& Moore, R. Social Realism, Knowledge and the Sociology of Education. Sage: New York.

Morais, A. M., \& Neves, I. P. (2001). Pedagogic social contexts: Studies for a sociology of learning. In Morais, A., Neves, I., Davies, B. \& Daniels, H. (Eds.), Towards a sociology of pedagogy: The contribution of Basil Bernstein to research. (185-221). New York: Peter Lang.

National Education Crisis Committee. (1992). Curriculum for post-apartheid education. Pretoria.

Nkomo, M. (1997). Pedagogy of domination towards democratic South Africa. Thornton Africa: World Press.

Ogunniyi, M. B., \& Hewson, M. G. (2008). Effect of an argumentation-based course on teachers' disposition towards a science-indigenous knowledge curriculum. Journal of Environmental and Science Education, 3(4), $159-177$

Ogunniyi, M. B. (1996). Science, technology and mathematics: The problem of developing critical human capital in Africa. International Journal of Science Education, 18(3), 267-284. https://doi.org/10.1080/0950069960180301

Sato, M.S. (2003). Curriculum and Teacher. Trans. By ZHONG, Qiquan. Beijing: Educational Science Publication Press.

Kermeling, W. G. (1994). Outcomes Based Education: critical Issues and answers. Arlington. American School Administrators.

Sampa, E. L. (2014). Forging a philosophical foundations of Outcomes Based Education. Paper presented at the Society for the Philosophical study of Education.

Spady, W. G. (1994). Outcomes Based Education: Critical Issues and Answers. The American Association of School Administrators.

Spady, W., \& Marshall, K. (1991). Beyond Traditional Outcomes-Based Education. Educational Leadership, 49(2), 18-23.

Stears M., \& Malcom C. (2005). Learners and teachers as co-designers of relevant science curricula. Perspectives in Education, 23(3), 21-43.

Themane, M.J. (2013). Understanding curriculum: A challenge to curriculum development in teacher education programme. South African Journal for Higher Education, 25, 1639-1651

Young, M. (2013). Overcoming the crisis in curriculum theory: a knowledge -based approach. Journal of Curriculum Studies, 45, 101-118. https://doi.org/10.1080/00220272.2013.764505

Zalaghi H., \& Khazaei M. (2016). The role of deductive and inductive reasoning in Accounting: Research and standard setting. Asian Journal of Finance and Accounting, 18, 334 -345. https://doi.org/10.5296/ajfa.v8i1.8148

Zarry, L. (2002). A multicultural science curriculum: Fact or Fantasy? Education Research Quarterly, 25, 3-10. 